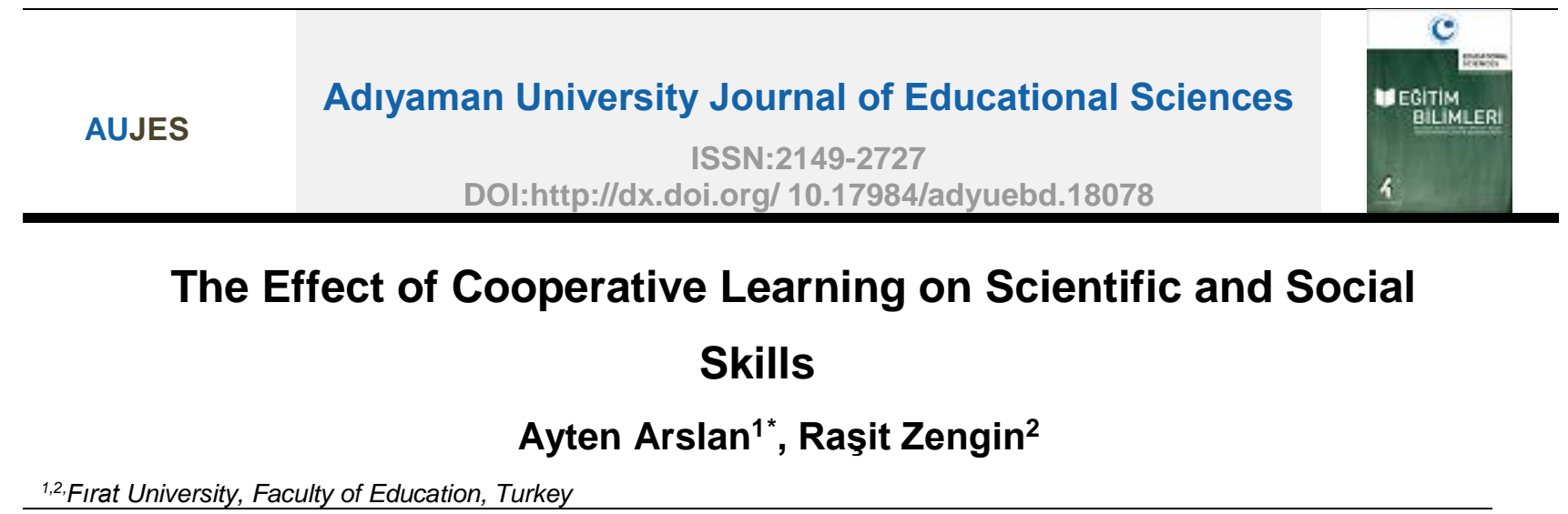

\begin{tabular}{l} 
ARTICLE INFO \\
\hline Article History: \\
Received \\
09.11 .2015 \\
Received in revised \\
form 25.01 .2016 \\
Accepted \\
16.02.2016 \\
Available online \\
30.06.2016
\end{tabular}

\begin{abstract}
In this research, effects of Cooperative Learning Method (CLM) and traditional learning method on university students' scientific and social skills at science teaching laboratory applications course were examined. 99 students that study Department of Science Teacher at Education Faculty of Firat University sampled this research. Experimental research design, including pre-test and post-test, was used in the study. The data of the research was collected using observation form and a semi-structured interview method. When analysing the data, arithmetic average, frequency and percentage were used. The interviews were recorded by a tape recorder and the observations were recorded by a video camera. Content analysis method was used in the analysis of the interviews. The results of the research has been found that cooperative learning have a positive impact on scientific and social skills.
\end{abstract}

Keywords:

(C) 2016 AUJES. All rights reserved

Cooperative Learning, Science Teaching, Laboratuary

\title{
Extended Abstract
}

\section{Methodology}

The objective of the study is to investigate whether there is a significant difference between laboratory activities conducted with learning together technique which is one of the cooperative learning techniques and those conducted with conventional instruction based on student behavior and social relationships. To this end, experimental design with pretestposttest control group was used in the study. Semi-structured interview and survey techniques were utilized for data collection.

\section{Study Group}

Study group consisted of 99 pre-service teachers that attended junior Science Teaching Laboratory Applications course at Firat University, Faculty of Education, Department of Science Education in 2010 - 2011 academic year fall semester in Elazığ province. In the study, groups were determined by random assignment method. A class is determined as the

\footnotetext{
* Corresponding author's address: Fırat University, Faculty of Education, Department of Science Teacher, Elazığ e-mail: aytenarslan23@gmail.com
} 
control group ( $n=51)$ while the other is the experimental group $(n=48)$. In the implementation process Learning Together technique was used in the experimental group.

\section{Data Collection Tool}

In the study, a survey form was used to determine the effects of cooperative learning method on student behavior, academic and social skills of the students in Science Teaching Laboratory Applications course. The researcher participated in the course as a participant observer. In this way, it was aimed to both not affect the behavior of the students and establish a close contact with groups. Thus, intra-group and inter-group activities were provided to examine more closely. Observations were conducted by a researcher positioned passively and far from the students and at a point that would not attract their attention during the course and based on the criteria set in the survey form. Video cameras were also used during the observations. The video cameras were placed at different locations to view the area where the researcher had the least angle of view and where they would affect the students' attention the least, and where they would cover the class as much as possible. Thus, the situations that come to pass in areas that the researcher could not observe or the details she or he could miss when taking notes could be caught.

A survey form developed by Altıparmak and Nakiboğlu (2002) was utilized in the study titled "Cooperative Learning in High School Biology Laboratory" including 8 main dimensions and 30 items related to observable behaviors of students. 5-level Likert-type measurement scale was used to determine the effects of Cooperative Learning Method (CLM) on behavior, academic and social skills of students. Likert-scale is a 5 level grading scale from 1 to 5. During group work, students' self-control, device and use the device, data collection and use of information sources, work participation, discussion and evaluation, encouragement and reporting results skills was graded by giving points from 1 to 5 , and using the sum of these points arithmetic mean values are calculated. The choices available on the scale and point ranges are presented in Table 1 . The findings were interpreted within this framework.

Table 1. Scale Selections and Point Ranges

\begin{tabular}{|l|c|l|l|}
\hline \multicolumn{1}{|c|}{ Choice } & Points & Point Range & \multicolumn{1}{|c|}{ Interpretation } \\
\hline Always & 5 & $4,20-5,00$ & Highly successful \\
\hline Mostly & 4 & $3,40-4,19$ & Successful but could be improved \\
\hline Often & 3 & $2,60-3,39$ & Average \\
\hline Rarely & 2 & $1,80-2,59$ & Poor \\
\hline Never & 1 & $1,00-1,79$ & Çok Zayıf \\
\hline
\end{tabular}


In the study, individual interviews were conducted with 21 pre-service teachers to obtain detailed information about the effect of cooperative learning method on students. Interviews were recorded with an audio recorder. When deemed necessary, additional questions were asked to the students.

\section{Data Analysis}

SPSS statistical software was utilized for the analysis of the data obtained via the survey form in the study. Arithmetic mean was used when determining the distributions considering the characteristics of problems and sub-problems.

Analysis of the interviews was conducted with N-Vivo qualitative data analysis software. The data obtained from the interviews were transcribed into text in computerized environment to prepare the data for analysis. The questions asked about the implementation of cooperative learning method were considered as sub-headings and several concepts were identified based on the views that the students expressed on each question. Thus, the number of students that were concentrated on the same concept was determined. These texts were coded with open symbols to facilitate processing. Following the coding process, a code list was formed and the common items were identified and the main themes of the study findings were created. Percent and frequency of the answers of the students were determined. In this context, these themes were defined in the findings section and then interpreted.

\section{Results and Suggestion}

Based on the findings of the study;

1. The findings obtained from the survey form demonstrated that cooperative learning method had positive effects on student behavior compared to conventional learning method. It was determined that conventional learning method had positive effects on students' academic and social skills.

2. As a result of the analysis of the views of the students on cooperative learning method, it was determined that they shared positive thoughts on the method and found the method useful.

Based on the results of the survey form, it was determined that students always conducted a preliminary preparation before the class. Thus, it was observed that they have gathered information about the experiments, came to class with different resources, and utilized these resources during the class. It was also observed that this preliminary preparation stimulated their will of learning, directed them to act with a plan and cooperate with each other. It was observed that the students asked questions, made explanations, 
exchanged information and ideas and continuously communicated through in-group and between-groups discussions, and listened, criticized and encouraged one another (compliments, approvals, support, motivation for participation, etc.). Students found opportunities to be together with their peers that they had never had an opportunity to work with in this process. Thus, they had an opportunity to get to know each other better and establish communications. It was identified that the students were active all the time in this process. These behaviors were seldom observed in the control group.

Based on the results of the study that are explained above, it could be concluded that cooperative learning had positive effects on social skills. Due to the roles played in cooperative learning groups, it was observed that the responsibilities of the students in the group and their commitment to each other increased. Encouraging and promoting the student increased participation and self-confidence. Students assisted each other and learned to work within groups with cooperative learning. They do not only thinking about themselves, but also their teammates and act with responsibility for them. Students learned team spirit, to get motivated, to develop the team members' skills by helping each other, to listen to their peers, constructive criticism, to study in order, to create and share ideas with their friends through creative learning in this study.

The findings derived from the views of the students on benefits of the method displayed similar results. The responses of the participants demonstrated that the items of "providing meaningful learning, socialization, eliminating conceptual mistakes, providing being active, looking at facts from different perspectives, increasing motivation, self-esteem, developing responsibility, working together, learning to share and exchanging information and ideas, and reducing workload" were loaded. Consequently, it could be argued that students expressed positive views about the method and found it beneficial. Application showed that the fact that every student was assigned different tasks created a will to fulfill this task and since all workload was not assigned to one student decreased the students' individual burdens. The students were in constant communication with each other before and after the experiments and the groups were determined by random draw each week to form the groups with students that have not worked with each other before, resulting in better socialization and establishing communications with peers they did not know before. Furthermore, it gave the opportunity to get to know one another better. In addition, intragroup and inter-group discussions made the students more active, provided them a new perspective, thus creating more meaningful learning. Arriving at the class more prepared motivated the students better, and increased their self-esteem in fulfilling their tasks.

As a result, learning together with the collective learning technique helps develop students' application skills in technical and scientific processes such as understanding the objective of the experiment, conducting the experiment independently, observing and 
scrutinizing the results, finding the sources of error and searching for solutions, and creating new ideas. It was further observed that laboratory activities were fun with cooperative learning and research, understanding and comprehension skills of the students improved considerably.

The following recommendations were considered to be appropriate in the light of the findings of the study. Further studies could investigate other cooperative learning techniques on social and scientific skills based on the beneficial effects of collective learning technique of the cooperative learning method. Research periods could be prolonged to observe more permanent effects. Different techniques of cooperative learning method could be compared and their effects could be observed. Cooperative learning technique could be utilized in other courses given its positive effects. The effects of cooperative learning techniques on different subjects in science and technology course could be scrutinized. 


\title{
İşbirlikli Öğrenme Yönteminin Bilimsel ve Sosyal Beceriler
}

\author{
Üzerindeki Etkisi
}

\section{Ayten Arslan ${ }^{1 *}$, Raşit Zengin ${ }^{2}$}

1,2, Fırat Üniversitesi, Eğitim Fakültesi, Türkiye

MAKALE BILGI

Makale Tarihçesi:

Alındı 09.11.2015

Düzeltilmiş hali

alındı 25.01.2016

Kabul edildi

16.02.2016

Çevrimiçi yayınlandı 30.06.2016

\section{ÖZET}

Bu araştırmada, İşbirlikli Öğrenme Yöntemi (IÖY) ile geleneksel öğrenme yönteminin, üniversite öğrencilerinin fen öğretimi laboratuar dersindeki bilimsel ve sosyal becerileri üzerindeki etkileri incelenmiştir. Araştırmanın örneklemini Fırat Üniversitesi Eğitim Fakültesi Fen Bilgisi Öğretmenliği 3.sınıfta okuyan 99 öğrenci oluşturmuştur. Araştırmada ön test-son test kontrol gruplu deneysel desen kullanılmıştır. Araştırma verileri gözlem formu ve yarı yapılandırımış görüşme tekniği ile toplanmıştır. Verilerinin analizinde aritmetik ortalama, frekans ve yüzde kullanılmıştır. Görüşmeler ses kayıt cihazıyla, gözlemler ise video kamera ile kayıt altına alınmıştır. Görüşmelerin analizinde içerik analiz yöntemi kullanılmıştır. Araştırma sonucunda İşbirlikli Öğrenme Yöntemi tekniklerinden birlikte öğrenme tekniğinin bilimsel ve sosyal beceriler üzerinde olumlu etkisi olduğu tespit edilmiştir.

(c) 2016 AUJES. Tüm hakları saklıdır

Anahtar Kelimeler:

İşbirlikli Öğrenme, Fen Öğretimi, Laboratuar

\section{Giriş}

Bilimsel ve teknolojik gelişmelerin hayatımıza etkisi günümüzde açık bir biçimde görülmektedir. Teknolojik gelişmeler gelecekte de hayatımızı etkilemeye devam edecektir. Bütün bu gelişmeler dikkatle incelendiğinde fen derslerinin neden önemli ve gerekli olduğunu anlamamıza yardımcı olacaktır. Doğadaki her olay fenin bir alanıyla ilgili olduğundan fen bilimi yaşamın önemli bir parçasıdır. Fen ve teknoloji; canlı, cansız, doğa ile ilgili her türlü olayla ilgilenmektedir. Bu yüzden, fen ve teknoloji eğitiminin geliştirilmesi için bu alanda yenilikler yapılmış, bu yenilikler eğitim reformlarının bir parçası olmuştur (Doğru ve Kıyıcı, 2005).

Geleneksel öğretimde birçok problemlerle karşılaşılmaktadır. Bunların başında öğretilen bilgilerin kalıcı olmaması, öğrencilerin bilgiyi sınav için öğrenip sonra hızla unutması, bilgilerin bir kısmının öğrenciler tarafından anlaşılmaması ya da yanlış

\footnotetext{
*Sorumlu yazarın adresi: Fırat Üniversitesi, Eğitim Fakültesi, Illköğretim Fen Bilgisi Öğretmenliği Bölümü, Elazığ e-posta:aytenarslan23@gmail.com
} 
anlaşılması, öğrencilerin öğrendikleri bilgi ve becerileri sonraki hayatlarında kullanamaması gibi problemler gelmektedir. Geleneksel anlayıştan kaynaklanan bu tür sorunları gidermek için eğitimciler daha etkili, verimli ve çekici öğretim yöntemleri geliştirmek üzere bu yönde çalışmaya başlamışlardır (Aydede, 2006).

Öğrenci merkezli eğitim anlayışına göre öğrenci derste aktiftir. Öğrenci derste aktif olduğu için bilgiyi kendisi keşfeder, soru sorar, sorulara cevap arar, analizler ve sentezler yapar, arkadaşlarıyla tartışır, işbirliği yapar, deneyleri kendisi yapar, kendi cümlelerini kurar, sonuca ulaşmaya çalışır, kendi problemlerini kendisi çözer. Bu da öğrencilerde kendine güveni getirir. Tüm bunlar gerçekleşirken aktif öğrenme yöntemlerinde öğretmen pasif halde değildir; tam tersine öğretmen rehberlik yapma gibi büyük bir sorumluluk taşır. Öğrenci merkezli öğretim yaklaşımlarında öğretmen, öğrencilerin bilgileri kazanma yöntemlerini bulmalarına yardımcı olur. Öğretmen, dersin içeriğini ve yöntemlerini öğrenci merkezli olacak şekilde hazırlar (Bilgin, 2006).

Günümüzde Fen Bilgisi öğretiminin temel amacı, her şeyi bilen bireyler değil; karşılaştığı problemi çözmek için bilgiye ulaşabilen, ulaştığı bilgileri analiz ve sentez ederek problemin çözümünü gerçekleştiren, bilgi üreten bireyler yetiştirmektir. Bu amacı gerçekleştirebilmek için eğitim-öğretim alanında büyük gelişmeler olmuştur. Bu gelişmelerden biriside grupla öğrenme yöntemleridir. Grupla öğrenme yöntemleri her öğrenci için önemlidir. Farklı yetenekleri, gereksinimleri, öğrenme biçimleri olan öğrencilere göre gruplar oluşturulur ve öğrenciler bu gruplarda çalışmaya devam ederler. Grupta bulunan her öğrencinin, diğer öğrencilerle olumlu etkileşimde bulunması, araç-gereç, bilgi ve becerileri ortak paylaşması sağlanır. Ayrıca grup üyeleri konunun bir parçasından sorumlu olmakla birlikte, konuyla ilgili çalışmalarda da gruba katkıda bulunmalıdırlar (Cooper \& Mueck, 1990).

Grupla öğrenme yöntemlerinden biri de işbirlikli öğrenme yöntemidir (Şimşek, Doymuş ve Kızıloğlu, 2005; Ünlüsoy, 2006). İşbirlikli öğrenme yöntemi, eğitimöğretim aktivitelerinde yerini almaya başladığından günümüze kadar gelen uygulama sürecinde, bu yöntem ile çalışan araştırmacıların çalışmalarına paralel olarak değişik tekniklerle ve uygulamalarla eğitimde yerini almıştır. Bu teknikler; öğrencinin sayısına, ortamın sosyal yapısına, sınıfın fiziki yapısına ve uygulanacak ders ve dersin konusuna göre çeşitlilik göstermektedir (Doymuş, Şimşek ve Şimşek., 2005; Maloof \& White, 2005; Şimşek, Doymuş ve Şimşek., 2008).

Fen bilimleri eğitimi öğrencilere verimli, kullanışlı ve etkili olarak verilmelidir. Öğrencileri yarışmaya yönlendiren bir sistem, hem sosyal hem de akademik yönden 
gelişmelerine de engel olmaktadır. Arkadaşlarını rakip olarak gören bir öğrenciler onlarla iletişimini koparmaktadırlar. İşbirliğine gitmeyen bu öğrenciler öğrenmelerini kendi çabalarıyla sağlamaya çalışmaktadırlar. Fen Bilgisi eğitiminde işbirlikli öğrenme yönteminin kullanılmasının öğrencilerin, akademik ve sosyal becerilerine yönelik etkisini belirlemek için bu araştırma yapılmıştır.

\section{Yöntem}

\section{Araştırma Deseni}

Araştırmanın amacı Fen Öğretimi Laboratuar Uygulamaları dersinde, işbirlikli öğrenme yöntemi tekniklerinden birlikte öğrenme tekniğine dayalı laboratuar etkinlikleri ile geleneksel öğretimle yapılan laboratuar etkinlikleri arasında, öğrenci davranışları ve sosyal ilişkiler bakımından anlamlı bir farklııı olup olmadığını araştırmaktır. Bu amaçla araştırmada ön test-son test kontrol gruplu deneysel desen kullanılmışıı. Verileri toplamak amacıyla yarı yapılandııımış görüşme ve gözlem teknikleri kullanılmıştır.

\section{Çalışma Grubu}

Araştırmaya katılan çalışma grubunu Elazığ ilinde Fırat Üniversitesi Eğitim Fakültesi, Fen Bilgisi Öğretmenliği Bölümü, 2010-2011 güz döneminde öğrenim gören 3. sınıf Fen Öğretimi Laboratuar Uygulamaları dersini alan 99 öğretmen adayı oluşturmaktadır. Araştırmada gruplar seçkisiz atama yöntemi ile belirlenmiştir. Bir sınıf deney grubu $(n=48)$, diğer sınıf ise kontrol grubu $(n=51)$ olarak belirlenmiştir. Uygulama sürecinde deney grubunda Birlikte Öğrenme tekniği kullanılmıştır.

\section{Veri Toplama Aracı}

Araştırma kapsamında İşbirlikli öğrenme yönteminin, Fen Öğretimi Laboratuar Uygulamaları dersinde öğrencilerin davranışları, akademik ve sosyal becerileri üzerindeki etkilerini belirlemek amacıyla gözlem formu kullanılmıştır. Araştırmacı katıımcı gözlemci olarak derslere katılmıştır. Bu şekilde hem öğrencilerin davranışlarının etkilenmemesi amaçlanmış hem de gruplarla yakın temas kurulması amaçlanmıştır. Böylece grup içi ve gruplar arası etkinliklerin daha yakından incelenmesi sağlanmıştır. Gözlemler ders boyunca, gözlem formunda yer alan kriterler esas alınarak gerçekleşmiştir. Gözlem uygulamalarında video kameralar kullanıımıştır. Kullanılan video kameralar, araştırmacının görüş açısının en az olduğu, 
öğrencilerin dikkatini en az etkileyecek ve laboratuarı mümkün olduğu kadar çok kapsayacak bir şekilde laboratuarın birkaç bölgesine yerleştirilmiştir. Böylece araştırmacının uzak olduğu yerlerde olup biten durumlarla, not alırken kaçırabileceği ayrıntıların daha sonra yakalanabileceği düşünülmüştür.

Gözlem formu Altıparmak ve Nakiboğlu (2002),tarafından “Lise Biyoloji Laboratuarlarında İşbirlikli Öğrenme" adlı çalışmada kullanılmış öğrencilerin gözlenebilecek davranışlarını içeren 8 ana başlık altında 30 maddeden oluşmaktadır. IÖY' nin öğrenci davranışlarına, akademik ve sosyal becerilerine etkilerini belirleyebilmek için, beşli likert tipi derecelendirme ölçeği kullanılmıştır. Likert ölçeği 1'den 5'e kadar olan derecelendirme ölçeği olup, ölçek 5 eşit parçaya bölünmüş ve her seçeneğe karşılık gelen puan aralıkları da belirlenmiştir. Grup çalışmaları sırasında, öğrencilerin otokontrol, alet ve cihazları kullanma, veri toplama, bilgi kaynaklarını kullanabilme, çalışmaya katılım, tartışma ve irdeleme, cesaretlendirme ve sonuçları rapor etme gibi becerilerine 1'den 5'e kadar puan verilerek, bu puanların toplamlarının aritmetik ortalama değerleri hesaplanmıştır. Ölçek seçenekleri ve puan aralıkları Tablo 1'de verilmiştir. Bulguların yorumlanması bu çerçevede yapılmıştır.

Tablo 1. Ölçek Seçenekleri Ve Puan Aralıkları

\begin{tabular}{llll}
\hline Seçenekler & Puanlar & Puan Aralığı & Değerlendirme \\
\hline Her Zaman & 5 & $4,20-5,00$ & Üst düzeyde başarılı \\
Çoğunlukla & 4 & $3,40-4,19$ & $\begin{array}{l}\text { Başarılı fakat } \\
\text { gereken }\end{array}$ \\
Sık Sık & 3 & $2,60-3,39$ & Vasat \\
Nadiren & 2 & $1,80-2,59$ & Zayıstirilmesi \\
Hiçbir Zaman & 1 & $1,00-1,79$ & Too Poor \\
\hline
\end{tabular}

Araştırmada, işbirlikli öğrenme yönteminin öğrenciler üzerindeki etkisine yönelik detaylı bilgiler elde etmek amacıyla deney grubunda görüşmelere katılmaya gönüllü 21 öğretmen adayı ile bireysel olarak görüşmeler yapılmıştır. Görüşmeler ses kayıt cihazı ile kayıt altına alınmıştır. Gerek görüldüğünde öğrencilere bazı ek sorularda yöneltilmiştir. 


\section{Verilerin Analizi}

Araştırma süresince gözlem formundan elde edilen verilerin çözümlenmesi amacıyla SPSS istatistik programı kullanılmıştır. Problem ve alt problemlerin özelliği dikkate alınarak dağıımları belirlemede aritmetik ortalama kullanılmıştır.

Görüşmelerin analizi için için N-Vivo nitel veri analiz programından faydalanılmıştır. Görüşmelerden elde edilen veriler bilgisayar ortamında yazıya aktarılmış ve analize uygun hale dönüştürülmüştür. İşbirlikli öğrenme yönteminin uygulaması hakkında sorulan sorular birer alt başlık gibi değerlendirilerek her soru için öğrencilerin ifade ettikleri görüşleri üzerinden çeşitli kavramlar belirlenmiştir. Bu yolla kaç öğrencinin aynı kavram üzerinde durduğu ortaya konmuştur. Bu metinler işlemeyi kolaylaştırmak amacıyla kısa, basit ve açık semboller halinde kodlanmıştır. Kodlamanın ardından, kod listesi oluşturularak ortak yönleri belirlenmiş ve araştırmanın bulgularının ana hatlarını oluşturacak temalar oluşturulmuştur. Öğrencilerin verdikleri cevapların yüzde ve frekansları belirlenmiştir. Bu çerçevede temalar, bulgular kısmında tanımlanmış ve yorumlanmıştır.

\section{Uygulama}

Uygulama öncesinde 'birlikte öğrenme' tekniği öğrencilere tanıtılmıştır. Derse başlamadan önce gruplar kura ile belirlenmiştir. İşbirlikli gruplardaki öğrencilere rolleri rastgele dağıtılmıştır. Bu roller gözlemci; kontrolör, sözcü, kaydedici, malzemeci ve okuyucudur. Her dersten önce rastlantısal olarak 6'sar kişilik gruplar oluşturulmuş ve grup üyeleri görevlerini kendi aralarında paylaşmışlardır. Bu şekilde deneyler yapılmış, raporlar yazılmış ve sınıfa sunulmuştur. Deneyle ilgili ve diğer kümelerden gelen sorular yanıtlanmıştır. Değerlendirme rastlantısal olarak seçilen bir kümenin deneyini anlatması, sınıfa raporlarını sunmaları seklinde yapılmıştır Her ders küme notları not edilmiştir. Görevler her ders değiştirilmiştir. Uygulamalar sona erdikten sonra deney grubundan seçilen gönüllü 21 öğrenci ile görüşmeler yapılmıştır. Kontrol grubunda ise kendi istekleri doğrultusunda altışarlı gruplara ayrılmış ve deneyler yapılmıştır. Öğrenciler deneyle ilgili raporlarını hazırlayarak bir sonraki hafta öğretmenlerine teslim etmişlerdir. 


\section{Bulgular ve Yorum}

Bu bölümde, önceki bölümde sunulan araştırma yöntemi ile toplanan verilerin, istatistiksel tekniklerle yapılan çözümlemeleri sonucu elde edilen bulgulara ve bu bulgulara ilişkin yorumlara yer verilmiştir.

Gözlem sonuçları, gözlem formunun alt başlıkları dikkate alınarak; Otokontrol, Alet ve Cihazlar Kullanabilme, Veri Toplama, Bilgi Kaynaklarını Kullanabilme, Tartışma ve İrdeleme, Cesaretlendirme, Çalışmaya Katılım, Sonuçları Rapor Edebilme davranışlarına ilişkin sonuçlar olmak üzere 8 ana başlık altında ele alınmıştır. Deney ve Kontrol gruplarının aritmetik ortalamalarına bakılmış ve yorumlanmıştır. Kaydedilen gözlem bulgularına aşağıda yer verilmiştir.

Deney ve kontrol gruplarının otokontrol davranışlarına ilişkin bulgular ve yorum Tablo 2'de verilmiştir.

Tablo 2. Deney ve Kontrol Gruplarının Otokontrol Davranışlara İlişkin Aritmetik Ortalama Sonuçları

\begin{tabular}{lcc} 
DAVRANIŞLAR & Deney Grubu & Kontrol Grubu \\
& $\overline{\mathbf{X}}$ & $\overline{\mathbf{X}}$ \\
\hline Oto Kontrol & $\mathbf{4 , 1 7}$ & $\mathbf{2 , 5 2}$ \\
Öğrenmeye İstek & 4,00 & 2,58 \\
Planlı Hareket & 4,33 & 2,00 \\
Ön Hazırlık & 4,00 & 2,50 \\
Materyalleri Yerine Koyma & 4,33 & 3,00 \\
\hline
\end{tabular}

Tablo 2'ye göre, deney grubunun otokontrol ana başlığına ilişkin aritmetik ortalaması $(\bar{X}=4,17)$, kontrol grubunun ortalamasından $(\bar{X}=2,52)$ yüksektir. $B u$ bulguya göre İÖY ile deney grubu öğrencilerinin otokontrol davranışları gösterme sıklığı kontrol grubundan daha fazladır. Yani otokontrol davranışları deney grubu öğrencileri çoğunlukla gerçekleştirirken, kontrol grubu öğrencileri nadiren gerçekleştirmektedir. Alt başlıklara bakıldığında deney grubu öğrencilerinin planlı hareket ve materyalleri yerine koyma davranışlarını her zaman meydana getirirken, kontrol grubu öğrencileri bu davranışları nadiren ve sık sık sergilemektedirler.

Deney ve kontrol gruplarının alet ve cihazları kullanma davranışına ilişkin aritmetik ortalama sonuçları Tablo 3' de verilmiştir. 
Tablo 3. Deney ve Kontrol Gruplarının Alet Ve Cihazları Kullanma Davranışına İlişkin Aritmetik Ortalama Sonuçları

DAVRANIŞLAR

Alet Ve Cihazları Kullanma

Alet ve Cihazları Tanıma

Alet ve Cihazları Kullanabilme

Alet ve Cihazları Paylaşma
Deney Grubu

$\overline{\mathrm{X}}$

3,92

4,00

4,00

3,75
Kontrol Grubu

$\overline{\mathrm{X}}$

2,62

3,00

3,00

2,00

Tablo 3'e göre, deney grubunun alet ve cihazları kullanma ana başlığına ilişkin aritmetik ortalaması ( $\bar{X}=3,92)$, kontrol grubunun ortalamasından ( $\bar{X}=2,62)$ yüksektir. Bu bulguya göre deney grubu öğrencilerinin otokontrol davranışları gösterme sıklığı kontrol grubundan daha fazladır. Yani alet ve cihazları kullanabilme davranışlarını deney grubu öğrencileri çoğunlukla gösterirken, kontrol grubu öğrencileri sık sık göstermektedirler. Alt başlıklara bakıldığında alet ve cihazları tanıma ve kullanabilme davranışlarının deney ve kontrol öğrencileri tarafından çoğunlukla yapılırken, paylaşma davranışını ise deney grubu öğrencilerinin çoğunlukla, kontrol grubu öğrencilerinin ise nadiren gerçekleştirdikleri belirlenmiştir.

Deney ve kontrol gruplarının veri toplama davranışına ilişkin aritmetik ortalama sonuçları Tablo 4' de verilmiştir.

Tablo 4. Deney ve Kontrol Gruplarının Veri Toplama Davranışına İlişkin Aritmetik Ortalama Sonuçları

\begin{tabular}{lll}
\hline DAVRANIŞLAR & Deney Grubu & Kontrol Grubu \\
& $\overline{\mathbf{X}}$ & $\overline{\mathbf{X}}$ \\
\hline Veri Toplama & $\mathbf{4 , 1 3}$ & $\mathbf{2 , 1 3}$ \\
Gözlemleme & 4,33 & 2,81 \\
Not Alma & 3,81 & 2,08 \\
Deneyle İlgili Bilgi Toplama & 4,25 & 1,80 \\
\hline
\end{tabular}

Tablo 4'de göre, deney grubunun veri toplama ana başlığına ilişkin aritmetik ortalaması $(\bar{X}=4,13)$, kontrol grubunun ortalamasından $(\bar{X}=2,13)$ yüksektir. Bu 
bulguya göre deney grubu öğrencilerinin veri toplama davranışları gösterme sıklığı kontrol grubundan daha fazladır. Yani bu davranışları deney grubu öğrencileri çoğunlukla gösterirken, kontrol grubu öğrencileri nadiren göstermektedirler. Alt başlıklara bakıldığında gözlemleme ve deneyle ilgili bilgi toplama davranışlarını deney grubu öğrencileri her zaman, kontrol grubu öğrencileri sık sık ve nadiren gerçekleştirdikleri belirlenmiştir.

Deney ve kontrol gruplarının bilgi kaynaklarını kullanabilme davranışına ilişkin aritmetik ortalama sonuçları Tablo 5' te verilmiştir.

Tablo 5. Deney ve Kontrol Gruplarının Bilgi Kaynaklarını Kullanabilme Davranışına İlişkin Aritmetik Ortalama Sonuçları

Deney Grubu

$\overline{\mathbf{X}}$

3,92

4,42

3,42
Kontrol Grubu

$\overline{\mathbf{X}}$

1,40

1,81

1,00

Tablo 5'e göre, deney grubunun alet ve cihazları kullanma ana başlığına ilişkin aritmetik ortalaması ( $\bar{X}=3,92)$, kontrol grubunun ortalamasından $(\bar{X}=1,40)$ yüksektir. $\mathrm{Bu}$ bulguya göre deney grubu öğrencilerinin veri toplama davranışları gösterme sıklığı kontrol grubundan daha fazladır. Yani bu davranışları deney grubu öğrencileri çoğunlukla gösterirken, kontrol grubu öğrencileri hiçbir zaman göstermemektedirler. Alt başlıklara bakıldığında, deney grubunun deney kılavuzunu okuma davranışını her zaman gerçekleştirirken, kontrol grubunun nadiren ve deneyle ilgili diğer dokümanları okuma davranışını okuma davranışının deney grubu öğrencileri tarafından çoğunlukla gerçekleştirilirken, kontrol grubu öğrencileri tarafından hiçbir zaman gerçekleştirilmediği belirlenmiştir.

Deney ve kontrol gruplarının tartışma ve irdeleme davranışına ilişkin aritmetik ortalama sonuçları Tablo 6' da verilmiştir. 
Tablo 6. Deney ve Kontrol Gruplarının Tartışma ve İrdeleme Davranışına İlişkin Aritmetik Ortalama Sonuçları

\begin{tabular}{lcc}
\hline DAVRANıŞLAR & $\begin{array}{c}\text { Deney } \\
\text { Grubu }\end{array}$ & $\begin{array}{c}\text { Kontrol } \\
\text { Grubu }\end{array}$ \\
\hline Tartışma Ve İrdeleme & 3,95 & 2,28 \\
Deney Sonuçları Üzerinde Tartışma & 4,00 & 2,42 \\
Soruları Cevaplama & 4,00 & 2,50 \\
Soru Sorma & 4,00 & 2,42 \\
Dinleme & 4,25 & 2,50 \\
Açıklama Yapma & 4,00 & 2,42 \\
Fikirlere Saygı Duyma & 4,00 & 2,58 \\
Fikirleri Eleştirme & 3,67 & 1,77 \\
Diğer Üyelerin Anlayıp Anlamadığını Kontrol Etme & 3,67 & 1,67 \\
\hline
\end{tabular}

Tablo 6' ya göre, deney grubunun Tartışma ve İrdeleme ana başlığına ilişkin aritmetik ortalaması ( $\bar{X}=3,95)$, kontrol grubunun ortalamasından $(\bar{X}=2,28)$ yüksektir. $\mathrm{Bu}$ bulguya göre deney grubu öğrencilerinin tartışma ve irdeleme davranışlarını gösterme sıklığı kontrol grubundan daha fazladır. Yani tartışma ve irdeleme davranışlarının deney grubu öğrencileri tarafından çoğunlukla, kontrol grubu öğrencileri tarafından ise nadiren gerçekleştirildikleri belirlenmiştir. Alt başlıklara bakıldığında, dinleme davranışının deney grubu öğrencileri tarafından her zaman, kontrol grubunun nadiren, diğer üyelerin anlayıp anlamadıklarını kontrol etme ve fikirleri eleştirme davranışlarının deney grubu öğrencileri tarafından çoğunlukla yapılırken, kontrol grubu öğrencileri tarafından hiçbir zaman yapılmadığı belirlenmiştir.

Deney ve kontrol gruplarının cesaretlendirme davranışına ilişkin aritmetik ortalama sonuçları Tablo 7' de verilmiştir.

Tablo 7. Deney ve Kontrol Gruplarının Cesaretlendirme Davranışına İlişkin Aritmetik Ortalama Sonuçları

\begin{tabular}{lll} 
DAVRANIŞLAR & Deney Grubu & Kontrol Grubu \\
& $\overline{\mathbf{x}}$ & $\overline{\mathbf{X}}$ \\
\hline Cesaretlendirme & 3,31 & 1,67 \\
Onaylama & 3,90 & 1,81 \\
Destekleme & 3,58 & 1,81 \\
Övgü & 2,75 & 1,25 \\
Katılmaya Özendirme & 3,00 & 1,81
\end{tabular}


Tablo 7' ye göre, deney grubunun cesaretlendirme ana başlığına ilişkin aritmetik ortalaması ( $\bar{X}=3,31)$, kontrol grubunun ortalamasından ( $\bar{X}=1,82)$ yüksektir. Bu bulguya göre IÖY ile deney grubu öğrencilerinin cesaretlendirme davranışlarını gösterme sıklığı kontrol grubundan daha fazladır. Yani bu davranışları deney grubu öğrencileri sık sık gösterirken, kontrol grubu öğrencileri hiçbir zaman göstermektedir. Alt başlıklara bakıldığında, onaylama, destekleme, övgü davranışını deney grubu öğrencileri sık sık gösterirken, kontrol grubu öğrencileri hiçbir zaman göstermedikleri belirlenmiştir.

Deney ve kontrol gruplarının çalışmaya katılım davranışına ilişkin aritmetik ortalama sonuçları Tablo 8 ' de verilmiştir.

Tablo 8. Deney ve Kontrol Gruplarının Çalışmaya Katılım Davranışına İlişkin Aritmetik Ortalama Sonuçları

DAVRANIŞLAR

Deney

Kontrol

\begin{tabular}{lrc} 
& Grubu & Grubu \\
\hline Çalışmaya Katılım & 4,23 & 2,56 \\
Deneyle Ilgili Konuşma & 4,33 & 2,50 \\
Aktif Olma & 4,00 & 2,35 \\
Alet ve Cihazları Amaca Uygun Kullanma & 4,33 & 2,88 \\
Birlikte Çalışma & 4,25 & 2,50 \\
\hline
\end{tabular}

Tablo 8' e göre, deney grubunun Çalışmaya Katılım ana başığına ilişkin aritmetik ortalaması $(\bar{X}=4,23)$, kontrol grubunun ortalamasından $(\bar{X}=2,50)$ yüksektir. $\mathrm{Bu}$ bulguya göre deney grubu öğrencilerinin veri toplama davranışları gösterme sıkığı kontrol grubundan daha fazladır. Alt başlıklara bakıldığında deneyle ilgili konuşma, birlikte çalışma ve alet cihazları amaca uygun kullanma davranışlarının deney grubu tarafından her zaman, kontrol grubu öğrencileri tarafından nadiren ve sık sık yapıldıkları belirlenmiştir. Aktif olma davranışını ise deney grubu çoğunlukla gerçekleştirirken, kontrol grubu nadiren gerçekleştirmektedir.

Deney ve kontrol gruplarının sonuçları rapor etme davranışına ilişkin aritmetik ortalama sonuçları Tablo 9' da verilmiştir. 
Tablo 9. Deney ve Kontrol Gruplarının Sonuçları Rapor Etme Davranışına İlişkin Aritmetik Ortalama Sonuçları

\begin{tabular}{lll}
\hline DAVRANIŞLAR & Deney Grubu & Kontrol Grubu \\
& $\overline{\mathbf{X}}$ & $\overline{\mathbf{X}}$ \\
\hline Sonuçları Rapor Etme & 5,00 & 2,94 \\
Raporu Yazılı Sunma & 5,00 & 3,00 \\
Sözlü Sunma & 5,00 & 2,88 \\
\hline
\end{tabular}

Tablo 9' a göre, deney grubunun Sonuçları rapor etme ana başlığına ilişkin aritmetik ortalaması ( $\bar{X}=5,00)$, kontrol grubunun ortalamasından $(\bar{X}=2,94)$ yüksektir. Bu bulguya göre IÖY ile deney grubu öğrencilerinin veri toplama davranışları gösterme sıklığı kontrol grubundan daha fazladır. Yani sonuçları rapor etme davranışını deney grubu her zaman gerçekleştirirken kontrol grubu nadiren gerçekleştirmektedir. Alt başlıklara bakıldığında raporları yazılı ve sözlü sunma davranışlarının da yapılma sıklığının kontrol grubundan fazla olduğu söylenebilir.

Gözlem sonuçlarına bakıldığında işbirlikli öğrenme yönteminin öğrencilerin hem sosyal hem de akademik yönlerden olumlu etkilerinin olduğu belirlenmiştir. Deney grubundaki öğrencilerin; otokontrol, alet ve cihazları kullanma, bilgi kaynaklarını kullanabilme, çalışmaya katıım, tartışma ve irdeleme, cesaretlendirme ve rapor edebilme gibi akademik ve sosyal becerilerini geliştirdikleri görülmektedir. Bu bulgular diğer araştırma sonuçları ile de desteklenmektedir (Okebukola, 1986; Baird, Lazarowitz \& Lazarowitz, 1992; Heady, 1993; Lazarowitz, Lazarowitz \& Baird, 1994; Posner \& Markstein, 1994; Zales \& Colosi, 1996; Trautwein, Racke \& Hillman 1997; Colosi \& Zales, 1998; Koprowski \& Perigo, 2000).

Öğrencilerin işbirlikli öğrenme yönteminin akademik ve sosyal ilişkilerine etkisine yönelik görüşlerinden elde edilen bulgular Şekil 1' de verilmiştir. 


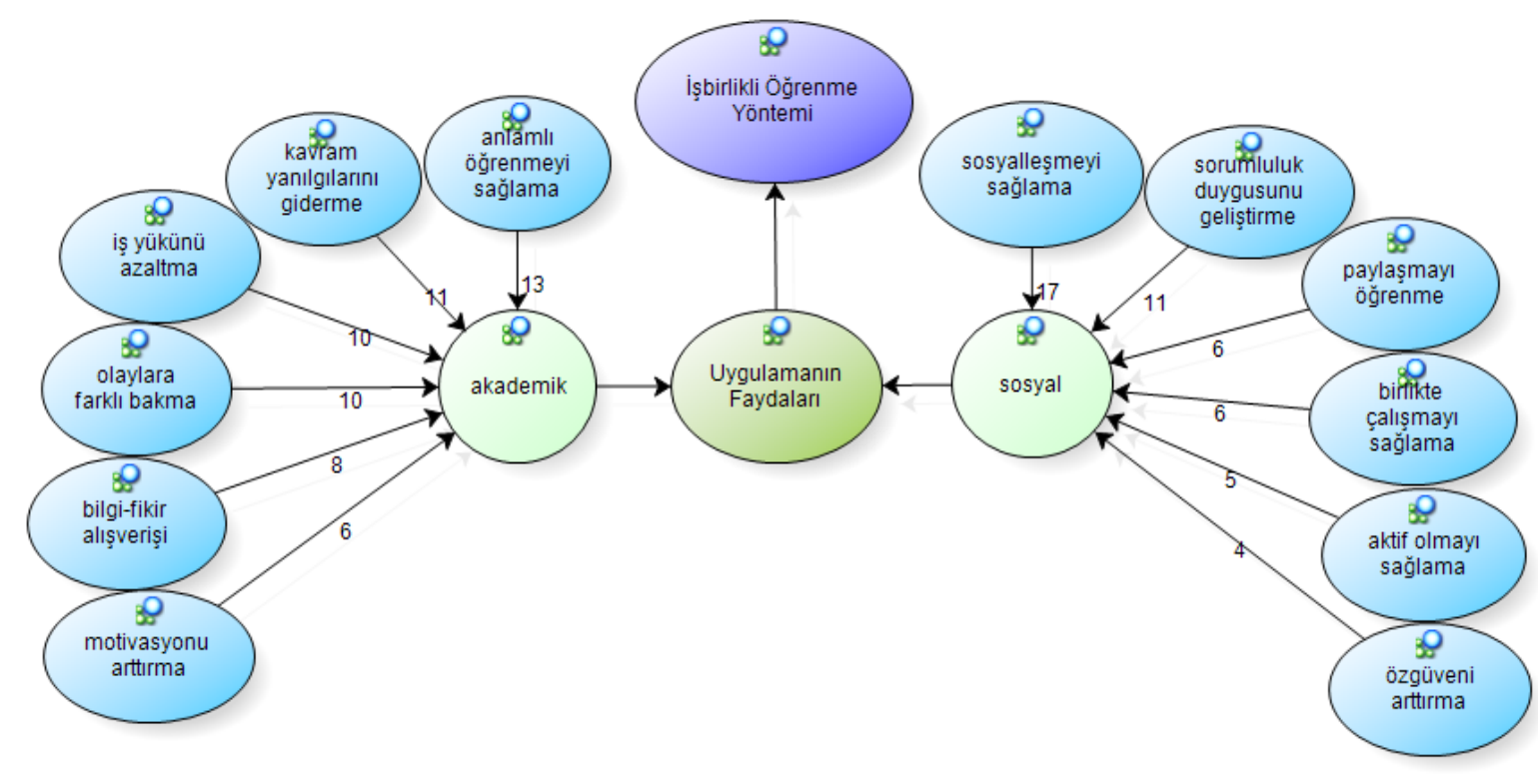

Şekil 1. İşbirlikli Öğrenme Yönteminin Sağladığı Faydalar

"Iş̧irlikli öğrenme yönteminin size sağladığı faydalar nelerdir?" şeklindeki görüşme sorusuna öğrencilerin verdiği cevaplar incelendiğinde; akademik ve sosyal olmak üzere iki başlıkta toplandığı görülmüştür. Akademik başığın altında“anlamlı öğrenmeyi sağlama, kavram yanılgılarını giderme, olaylara farklı açılardan bakmayı sağlama, motivasyonu arttırma, ,bilgi ve fikir alışverişi yapmayı sağlama ve iş yükünü azaltma" , sosyal başlığın altında ise "özgüveni arttırma, aktif olmayı sağlama, sorumluluk duygusunu geliştirme, sosyalleşmeyi sağlama, birlikte çalışmayı sağlama, paylaşmayı öğrenme başlıklarına ilişkin yüklemeler yaptıkları görülmüştür. Görüşmeler sonucu öğrencilerin yöntemin sağladığı sosyal faydalara verdikleri cevaplara ilişkin frekans ve yüzde sonuçları tablo 10'da verilmiştir.

Tablo 10. Sosyal Faydalara İlişkin Frekans ve Yüzde Sonuçları

\begin{tabular}{lcc}
\hline \multicolumn{1}{c}{ Sosyal Faydalar } & Frekans & Yüzde \\
\hline Sosyalleşmeyi sağlama & 17 & $\% 81$ \\
Özgüveni artırma & 4 & $\% 19$ \\
Aktif olmayı sağlama & 5 & $\% 24$ \\
Sorumluluk duygusunu geliştirme & 11 & $\% 52$ \\
Birlikte çalışmayı sağlama & 6 & $\% 29$ \\
Paylaşmayı öğrenme & 6 & $\% 29$
\end{tabular}

Bu sonuçlara bakıldığında, öğrencilerin \%81' inin yöntemin sosyalleşmeyi sağladığı, görüşünde birleştikleri söylenebilir. Yine öğrencilerin \%52'sinin yöntemi 
sorumluluk duygusunu geliştirme, \%29'unun birlikte çalışmayı sağlama ve paylaşmayı öğrenme, \%24'ünün aktif olmayı sağlama ve \%19 ‘ununözgüveni arttırma bakımından faydalı bulduğu söylenebilir.

Görüşmeler sonucu öğrencilerin yöntemin sağladığı akademik faydalara verdikleri cevaplara ilişkin frekans ve yüzde sonuçları tablo 11'de verilmiştir.

Tablo 11. Akademik Faydalara İlişkin Frekans ve Yüzde Sonuçları

\begin{tabular}{lcc}
\hline Akademik Faydalar & Frekans & Yüzde \\
\hline Anlamlı öğrenmeyi sağlama & 13 & $\% 62$ \\
Kavram yanılgılarını giderme & 11 & $\% 52$ \\
İş yükünü azaltma & 10 & $\% 48$ \\
Olaylara Farklı Bakma & 8 & $\% 38$ \\
Bilgi-fikir alışverişi & 8 & $\% 38$ \\
Motivasyonu arttırma & 6 & $\% 29$ \\
\hline
\end{tabular}

Bu sonuçlara bakıldığında, öğrencilerin \%62'sinin yöntemin anlamlı öğrenmeyi sağladığı görüşünde birleştikleri söylenebilir. Yine öğrencilerin \%52'sinin yöntemi kavram yanılgılarını giderme, \%29'unun motivasyonu arttırma, \%48'inin iş yükünü azaltma ve \%38'inin olaylara farklı bakma ve bilgi alışverişi yapmaya olanak sağlama bakımından faydalı bulduğu söylenebilir.

$\mathrm{Bu}$ görüşlere göre, öğrencilerin işbirlikli öğrenme yöntemini sosyal ve akademik açıdan faydalı buldukları söylenebilir. Uygulamanın yapılmasından son derece memnun oldukları ve yöntemi öğretim açısından, yukarıda başlıklar altında toplanan yönlerden yararlı buldukları bulgusuna ulaşıldığı söylenebilir.

Bu bulgular Tunçel (2006) ve Gülay'ın (2008) işbirlikli öğrenme yöntemi kullanarak yaptıkları araştırma bulguları ile örtüşmektedir. Görüşmelerden elde edilen sonuçlar da bu bulguyu desteklemektedir. Deney gruplarındaki öğrenciler yapılan görüşmelerde yardımlaşma, paylaşma, dayanışma, birlikte hareket etme, dinleme, cesaretlendirme ve motive etmeyi öğrendiklerini ve gerçekleştirdiklerini ifade etmişlerdir. Conway \& Gow (1988), işbirlikli öğrenme gibi küme çalışmaları içeren öğretim stratejilerinin sosyal becerileri geliştirdiğini, eğitim için bir çerçeve sağladığını belirtmiştir. Yine Johnson \& Johnson (1984), işbirlikli öğrenmede öğrencilerin ortak bir amacı başarmak için birlikte çalıştıklarını; işbirlikli öğrenme kullanıldığında 
öğrencilerin okulu ve birbirlerini daha çok sevdiklerini ve sosyal becerileri daha etkili kazandıklarını ifade etmişlerdir

Aşağıda görüşme yapılan 5 öğrencinin görüşme sorusuna ait cevaplarına yer verilmiştir:

Ö-1: "Daha önce bilgi sahibi olduğumuz konularla ilgili, farklı görüşlerle karşılaştık, yeni bilgiler öğrendik, hepimiz söz sahibiydik ve sürekli aktiftik. Görüşlerimizi rahatça paylaştık bu da daha başarılı olmamı sağladı.”

Ö-2: "Herkes üzerine düşen görevi yerine getrdi. Herkes bireysel olarak çalıştı, bu sorumluluğumuzu arttırdı. Bu da kendime olan güvenimi arttırdı."

Ö-3: "Grup tartışmalarında, grup olarak eksik yönlerimizi tamamladık. Görev dağılımı yapıldığından organizasyon sorunu olmadı, derse görevlerimiz gereği hazırlıklı olarak geldik bu da daha kalıcı öğrenme sağladı. Farklı arkadaşlarla çalışma fırsatı bulduk bu da onları daha yakından tanımamı sağladı, onlarla sosyal ilişkilerimizi olumlu yönde etkiledi."

Ö-4: "Birimizin eksik olduğu ya da iyi olmadığı bir alanda, gruptaki başka bir arkadaşımız ona yardımcı oluyordu, eksikliklerini gidermesine yardımcı oluyordu. Bu da bizim öğrenmelerimizi pekiştirme imkanı sağladı."

Ö-5: "Gruplarla deney sonlarında yapılan tartışmalarla, fikir alışverişi yaptık, birbirlerimizin eksikliklerini gördük, tamamlamaya çalıştık bu da konuları daha iyi öğrenmemi sağladı."

\section{Sonuç ve Tartışma}

Araştırmadan elde edilen bulgulara göre;

1. Gözlem formundan elde edilen bulgular ışığında, İşbirlikli öğrenme yöntemi öğrencilerin davranışları üzerinde, geleneksel öğrenme yöntemine göre daha olumlu etkilerde bulunmuştur. İşbirlikli öğrenme yönteminin öğrencilerin akademik ve sosyal becerileri üzerinde olumlu etkilerinin olduğu belirlenmiştir.

2. Öğrencilerin işbirlikli öğrenme yöntemine ilişkin görüşleri incelendiğinde, öğrencilerin yönteme ilişkin olumlu düşüncelerinin olduğu ve yöntemi faydalı buldukları tespit edilmiştir.

Gözlem formunda elde edilen sonuçlara göre, deney grubunda öğrencilerin dersten önce mutlaka bir ön hazırlık yaptıkları belirlenmiştir. Bu kapsamda deneylerle ilgili bilgiler toplandığı, farklı kaynaklarla derse gelindiği ve ders esnasında 
bu kaynaklardan faydalanıldığı gözlemlenmiştir. Bu ön hazırlığın onların öğrenme isteklerini tetiklediği, onları bir plan dahilinde hareket etmeye ve birlikte çalışmaya yönlendirdiği gözlemlenmiştir. Ders esnasında öğrencilerin sorular sorarak, açıklamalar yaparak, bilgi ve fikir alışverişlerinde bulunarak ve gruplar arası ve grup içi tartışmalarla sürekli iletişim içinde bulunduğu, birbirlerini dinleme, eleştirme ve cesaretlendirme (övgü, onaylama, destekleme, katılmaya özendirme vs.) davranışlarında bulunduğu gözlemlenmiştir. Öğrenciler daha önce hiç çalışma imkanı bulamadıkları arkadaşlarıyla bu süreçte daha sık bir arada olma imkanı bulmuşlardır. Böylece birbirlerini daha iyi tanıma ve iletişim kurma fırsatı yakalamışlardır. Öğrencilerin bu süreçte sürekli aktif oldukları tespit edilmiştir. Kontrol grubunda ise bu davranışlara çok az rastlanmıştır.

$\mathrm{Bu}$ araştırma, yukarıda açıklanan sonuca göre işbirlikli öğrenmenin sosyal beceriler üzerinde olumlu etkileri olduğunu saptamışlardır. İşbirlikli öğrenme gruplarındaki roller sayesinde, öğrencilerin grup içindeki sorumluluklarının ve birbirine bağlılıklarının arttığı gözlenmiştir. Öğrenciyi cesaretlendirmek ve teşvik etmek, katılımı ve özgüveni arttırmıştır. İşbirlikli öğrenme ile öğrenciler birbirlerinin öğrenmesine yardım etmekte ve grup içinde çalışmayı öğrenmektedir. Sadece kendilerini değil, takım arkadaşlarını da düşünüp onlara karşı sorumluluklarının bilip ona göre davranmaktadırlar. Öğrenciler bu çalışmada, işbirlikli öğrenme ile takım ruhunu, motive olmayı, birbirilerine yardım ederek grup üyelerinin becerilerini geliştirmeyi, karşılıklı iyi iletişimi, arkadaşını dinlemeyi, yapıcı eleştiri yapmayı, sırayla çalışmayı, arkadaşları ile fikir üretmeyi ve paylaşmayı öğrenmişlerdir

Öğrencilerin yöntemin faydalarına ilişkin görüşlerinden elde edilen sonuçlarda bu bulguları destekler niteliktedir. Katılımcıların cevapları incelendiğinde; " anlamlı öğrenmeyi sağlama, sosyalleşmeyi sağlama, kavram yanılgılarını giderme, aktif olmayı sağlama, olaylara farklı açılardan bakmayı sağlama, motivasyonu arttırma, özgüveni arttırma, sorumluluk duygusu geliştirme, birlikte çalışmayı sağlama, paylaşmayı öğrenme, bilgi ve fikir alışverişi yapmayı sağlama ve iş yükünü azaltma" başlıklarına ilişkin yüklemeler yaptıkları görülmüştür. Bu bulgular ışığında öğrencilerin yönteme ilişkin olumlu görüşler dile getirdikleri ve yöntemi yararlı buldukları sonucu ortaya çıkmıştır. Uygulamaya bakıldığında her bir öğrenciye farklı görevler verilmesi öğrencilerde bu görevi yerine getirme bilincini uyandırmıştır ve bütün işin bir öğrenciye yüklenmemesi öğrencilerin iş yükünü azaltmıştır. Deneylerin yapılmasından önce ve sonra öğrencilerin birbirleriyle sürekli iletişim halinde olması, 
öğrencilerin her hafta rastgele belirlenmiş kişilerle grup oluşturmaları onlara sınıfta daha önce çalışmadıkları kişilerle bir araya gelmeleri daha kolay iletişim kurmalarını ve sosyalleşmelerini sağlamıştır. Ayrıca öğrencilere birbirlerini daha iyi tanıma fırsatı vermiştir. Bunun yanı sıra grup içi ve gruplar arası bilgi ve fikir alışverişleri, tartışmalar ve paylaşımlar öğrencileri daha aktif hale getirmiş, olaylara farklı açılardan bakmalarını sağlamış, dolayısıyla daha anlamlı öğrenmeler meydana getirmiştir. Derse hazırlıklı gelmek öğrencilerin daha iyi motive olmalarını, üzerlerine düşen görevleri yerine getirmeleri kendilerine olan güvenlerinin artırmıştır.

İşbirlikli öğrenme ile laboratuar etkinliklerinin zevkli geçtiği, öğrencilerin araştırma, konuları anlama ve kavrama becerilerinin büyük ölçüde arttığı görülmüştür.

\section{Öneriler}

Elde edilen sonuçlara göre şu tavsiyeler uygun görülmektedir. İşbirlikli öğrenme yönteminin birlikte öğrenme tekniğinin olumlu etkilerine bakıldığında diğer işbirlikli öğrenme tekniklerinin sosyal ve bilimsel beceriler üzerindeki etkileri araştırılabilir. Araştırma süreleri daha uzun tutulabilir böylece daha kalıcı etkiler gözlemlenebilir. İşbirlikli öğrenme yönteminin farklı tekniklerinin karşılaştırmaları yapılabilir bunların etkileri gözlemlenebilir. İşbirlikli öğrenme tekniğinin bu olumlu etkilerine bakılarak diğer derslerde kullanılabilir. İşbirlikli öğrenme teknikleri fen ve teknoloji dersinin farklı konuları üzerindeki etkileri araştırılabilir.

\section{Kaynaklar}

Aydede, M.N., (2006). İlköğretim Altıncı Sınıf Fen Bilgisi Dersinde Aktif Öğrenme Yaklaşımını Kullanmanın Akademik Başarı, Tutum Ve Kalıcılık Üzerine Etkisi, Yayımlanmış Yüksek Lisans Tezi, Çukurova Üniversitesi, Adana.

Baird, H. J.; Lazarowitz, R.Ve Lazarowitz, R. H. (1992). Academic Achievement And Social Gains Of Differing Status Students Learning Science In Cooperative Groups. Cooperative Learning. 13 (1): 21-24.

Bilgin, G., (2006). “İşbirlikli Öğrenme”, (M. Bahar(Ed.), Fen Ve Teknoloji Öğretimi İçinde (S.137-158)), Ankara: Pegem Akademi Yayıncılık.

Colosi, J. C.Ve Zales, C. R. (1998). Jigsaw Cooperative Learning Improves Biology Lab Courses. Bioscience. Vol 48 (2): 118-124. 
Conway, R. N. F., \& Gow, L. (1988). Mainstreaming Special Class Students With Mild Handicaps Through Group İnstruction [Abstract]. Remedial And Special Education (Rase), 9 (5), 34-40

Cooper, J., Mueck, R., (1990). Student İnvolvement İn Learning: Cooperative Learning And College İnstruction, Journal On Excellence İn College Teaching, 1, 68-76.

Doğru, M., Kıyıcı, B. F., (2005). Fen Eğitimin Zorunluluğu, (Ed. M. Aydoğdu Ve T. Kesercioğlu), İlköğretimde Fen Ve Teknoloji Öğretimi İçinde(S. 2-8), Ankara: Anı Yayıncılık.

Doymuş, Kemal; Şimşek, Ümit; Şimşek, Ufuk., (2005). “ İşbirlikçi Öğrenme Yöntemi Üzerine Derleme Çalışması: I. İşbirlikçi Öğrenme Yöntemi Ve Yöntemle İlgili Çalışmalar”,Erzincan Eğitim Fakültesi Dergisi, 7(1),Ss.59-83.

Gülay, O. (2008). Ortaöğretim 9. Sınıf Beden Eğitimi Dersinde, İşbirlikli Oyunların Öğrencilerin Sosyal Beceri Düzeylerine Ve Beden Eğitimi Dersine Yönelik Tutumlarına Etkisi. Yüksek Lisans Tezi. Abant İzzet Baysal Üniversitesi, Sosyal Bilimler Enstitüsü, Bolu

Heady, J. E. (1993). Teaching Embryology Without Lectures And Without Traditional Laboratories. An Adventure In Innovation. Journal Of College Science Teaching, 23: 87-91.

Johnson, D. W., \& Johnson, R. T. (1984). Cooperative Small-Group Learning [Abstract]. Curriculum Report, 14 (1), 7 Pp. (Ed249625)

Koprowski,J.Ve Perigo,N.(2000). Cooperative Learning As A Tool To Teach Vertebrate Anatomy. American Biology Teacher. April. P. 282.

Lazarowitz, R. Ve Lazarowitz, Rachel-Hertz, Baird, J. H. (1994). Learning Science İn A Cooperative Setting:Academic Achievement And Affective Outcomes, Journal Of Research İn Science Teaching, 31(10) 1121-1131.

Maloof, Joan; White, Venessa K. B., (2005). "Team Study Training İn The College Biology Laboratory" Journal Of Biological Education, 39(3), Pp. 120-124. 
Okebukola, P. A. (1986). Cooperative Learning And Students' Attitudes To Laboratory Work. School Science And Mathematics, 86: 582-590.

Posner, H. B.\& Markstein, J. A. (1994). Cooperative Learning in Introductory Cell and Molecular Biology. Journal Of College Science Teaching. 23: 231-233.

Şimşek, Ü., Doymuş ,K., Ve Kızıloğlu N., 2005. Lise Düzeyinde Öğrenim Gören Öğrencilere Grupla Öğrenme Yönteminin Kazandırdığı Bilgi Ve Beceriler, Kastamonu Eğitim Dergisi , 13(1), 67-80.

Şimşek, Ümit., Doymuş, Kemal., Şimşek, Ufuk., (2008). “İşbirlikçi Öğrenme Yöntemi Üzerine Derleme Çalışması: Iı. İşbirlikçi Öğrenme Yönteminin Sınıf Ortamında Uygulanması", Erzincan Eğitim Fakültesi Dergisi,10 (1), Ss. 123-142.

Tunçel, Z. (2006). İşbirlikli Öğrenmenin Beden Eğitimi Başarısı, Bilişsel Süreçler Ve Sosyal Davranışlar Üzerindeki Etkileri. Doktora Tezi. Dokuz Eylül Üniversitesi, Eğitim Bilimleri Enstitüsü, İzmir.

Ünlüsoy, M., 2006. Orta Öğretim Fizik Müfredat Konularından "İmpuls Ve Momentum" Konularındaki Kavram Yanılgılarının Tespiti Ve Düzeltilmesinde İşbirlikli Yaklaşımın Etkisi, Yayımlanmamış Yüksek Lisans Tezi, Gazi Üniversitesi, Ankara

Trautwein, S. N.; Racke, A.Ve Hillman, B. (1996-97). Cooperative Learning in The Anatomy Laboratory. Journal Of College Science Teaching. Vol 26.

Zales, C., R.Ve Colosi J. C. (1996). Cooperative Learning İn Microbiology Laboratory. Journal On Excellence İn College Teaching, 7:127-161.

\section{Kaynak Gösterme}

Arslan, A., Zengin, R. (2016). İşbirlikli Öğrenme Yönteminin Bilimsel ve Sosyal Beceriler Üzerindeki Etkisi. Adıyaman Üniversitesi Eğitim Bilimleri Dergisi, 6(1), 23-45.

\section{Citiation Information}

Arslan, A., Zengin, R. (2016). The Effect of Cooperative Learning on Scientific and Social Skills. Adiyaman University Journal of Educational Sciences, 6(1), 2345. 